\title{
Education on sensor-augmented pump use improves glucose control in type-1 diabetic patients
}

\section{L'éducation à l'utilisation d'une pompe portable à insuline couplée à une mesure continue de la glycémie améliore l'équilibre glycémique de patients diabétiques de type 1}

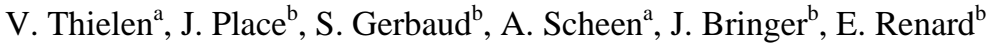 \\ ${ }^{a}$ University of Liège, Division of Diabetes, Nutrition and Metabolic Disorders, Department of Medicine, CHU Sart Tilman, 4000 Liège, \\ Belgium \\ ${ }^{\mathrm{b}}$ UMR CNRS 5232, Endocrinology Department, centre hospitalier universitaire de Montpellier, University of Montpellier, 34000 \\ Montpellier, France
}

Keywords : Glucose sensor ; Diabetes mellitus type-1 ; Education ; Paradigm Real Time ${ }^{\circledR}$

Mots clés : Mesure glycémique continue ; Diabète de type 1 ; Education ; PRT $^{\circledR}$

To the editor,

A rather large subset of type 1 diabetic patients fails to achieve their therapeutic goals in spite of a basal-bolus insulin regimen, frequent self-monitoring of capillary blood glucose (CBG) and tight medical follow-up [1]. Therefore, we investigated prospectively the effectiveness of specific education on the use of a sensoraugmented pump for improving glucose control in such poorly controlled type-1 diabetes patients in clinical practice.

Nine patients (six men, three women), aged $49 \pm 13$ (mean \pm SD) years, with type 1 diabetes since age $30 \pm 11$ years and a sustained glycated haemoglobin $\left(\mathrm{HbA}_{1 \mathrm{c}}\right)$ level greater than $7 \%$ were recruited into the study. All had poor metabolic control while under a basal-bolus insulin regimen (six patients by multiple daily insulin injections, three by portable insulin pump), using insulin analogues, and performing daily multiple CBG tests (5.5/day on average), and attending our clinic as outpatients every 2-3 months. All were taught how to use a sensor-augmented insulin pump (Paradigm Real Time ${ }^{\circledR}$, Medtronic MiniMed, Northridge, CA, USA) [2]. The enzymatic glucose sensor generates a continuous signal, which is transmitted online wirelessly to a pump, resulting in an estimation of blood glucose every $5 \mathrm{~min}$ on the pump screen. Recent glucose profiles, the current trend and hypo or hyperalarms are also available [2]. The glucose sensor was calibrated twice daily against CBG and replaced every 3 days by the patient. Patients were also taught how to adapt insulin delivery and carbohydrate intakes according to glucose levels and trends, while maintaining their usual CBG testing. A CBG test was requested before taking any action in cases of a hypo/hyper alarm. Outpatients visits were scheduled after 1.5, 3 and 6 months. Glucose control was assessed at baseline (BL or MO), and after 3 (M3) and 6 (M6) months of follow-up, from $\mathrm{HbA}_{1 \mathrm{c}}$ levels. In addition, CBG values recorded during the previous month and still in the metre's memory were carefully analyzed to calculate mean values, distribution across target ranges and indices of variability (standard deviation or SD, or mean amplitude of glycaemic excursions [MAGE]).

During the 6-month follow-up, $\mathrm{HbA}_{1 \mathrm{c}}$ levels were significantly decreased from $8.5 \pm 1.3 \%$ (BL) to $8.2 \pm 1.6 \%$ (M3, $P=0.049)$ and $7.8 \pm 0.7 \%(\mathrm{M} 6, P=0.047)$. A strongly positive correlation was observed between baseline $\mathrm{HbA}_{1 \mathrm{c}}$ levels and the reduction in $\mathrm{HbA}_{1 \mathrm{c}}$ levels after 6 months of follow-up $(r=0.78 ; P<0.001)$. While mean glucose levels were not significantly altered, the distribution of CBG values was improved with, in particular, a higher number of CBG measurements within the targets set $(80-140 \mathrm{mg} / \mathrm{dL} ; P<0.0001)$. However, no significant changes in indices of glucose variability were detected, perhaps because of the rather small number of participants in the study (Table 1). No severe hypoglycaemia or ketosis occurred during the follow-up, and no adverse events related to sensor-augmented pump use were reported. 
continuous information on glucose levels from a subcutaneous sensor, combined with insulin-pump delivery, can improve glucose levels in patients who fail to achieve sufficient control with state-of-the-art insulin therapy. However, given our study design, it is difficult to differentiate which part of the metabolic improvement was due to the new technology itself and which was due to the better overall management/education of the patient. In contrast to other studies, all patients in the present study were already being regularly followed by our department and had previously received intensive standardized education. Therefore, the global improvement in metabolic control observed in the present study may be largely attributed to the use of a sensor-augmented insulin pump. While confirmation by longer-term and controlled studies is still needed, teaching patients how to adapt their insulin therapy according to sensor data appears to be an invaluable approach towards obtaining significant benefits from the reduction of high blood-glucose excursions and from better overall glucose control.

Table 1 Parameters of blood glucose control before (M0 = baseline) and after (M3 = 3 months ; M6 $=6$ months) the use of a sensor-augmented insulin pump in nine patients with type 1 diabetes that was poorly managed with a basal-bolus regimen Mean \pm SD.

\begin{tabular}{|c|c|c|c|c|c|c|c|}
\hline & & M0 & & M3 & & M6 & ANOVA \\
\hline $\mathrm{HbA}_{1 \mathrm{c}}(\%)$ & & $8.5 \pm 1.3$ & & $8.2 \pm 1.6$ & & $7.8 \pm 0.7$ & 0.015 \\
\hline Mean capillary glucose level (mg/dL) & & $179 \pm 40$ & & $160 \pm 26$ & & $172 \pm 46$ & NS \\
\hline Standard deviation (mg/dL) & & 63 & & 62 & & 64 & NS \\
\hline MAGE (mg/dL) & & 102 & & 90 & & 92 & NS \\
\hline \multicolumn{8}{|c|}{ Analyses of 4343 capillary glucose measurements } \\
\hline Values 80-140 mg/dL (\%) & 28.6 & & 35.3 & & 32.0 & & 0.001 \\
\hline Values > 140 mg/dL (\%) & 59.5 & & 50.5 & & 54.8 & & \\
\hline Values $<80$ mg/dL(\%) & 11.9 & & 14.2 & & 13.2 & & \\
\hline
\end{tabular}

MAGE: mean amplitude of glycaemic excursions; NS: not significant.

Conflicts of interest : None of the authors has a conflict of interest to declare.

\section{Acknowledgements}

The present research project was supported by a fellowship from the Association de Langue Française pour l'Etude du Diabète et des Maladies Métaboliques (ALFEDIAM). The study group included: Liège: Professor A.J. Scheen, Dr V. Thielen; and Montpellier: Professor J. Bringer, Professor E. Renard. We also wish to thank all the clinicians and nurses who assisted in the follow-up of the study participants.

\section{References}

[1] Garg S, Schwartz S, Edelman S. Improved glucose excursions using an implantable real-time continuous glucose sensor in adults with type-1 diabetes. Diabetes Care 2004;27:734-8.

[2] Danne T, Lange K, Kordonouri O. Real-time glucose sensors in children and adolescents with type-1 diabetes. Horm Res 2008;70:193202.

[3] Fabiato K, Buse J, Duclos M, Largay J, Izlar C, O'Connell T, et al. Clinical experience with continuous glucose monitoring in adults. Diabetes Technol Ther2009;1l:S93-103.

[4] The Juvenile Diabetes Research Foundation Continuous Glucose Monitoring Study Group. Continuous glucose monitoring and intensive treatment of type-1 diabetes. N Engl J Med 2008;359:1464-76.

[5] Deiss D, Bolinder J, Riveline JP, Battelino T, Bosi E, Tubiana-Rufi N, et al. Improved glycemic control in poorly controlled patients with type-1 diabetes using real-time continuous glucose monitoring. Diabetes Care 2006;29:2730-2.

[6] Hirsch IB, Abelseth J, Bode BW, Fischer JS, Kaufman FR, Mastro-totaro J, et al. Sensor-augmented insulin pump therapy: results of the first randomized treat-to-target study. Diabetes Technol Ther 2008; 10: 377-83.

[7] Raccah D, Sulmont V, Reznik Y, Guerci B, Renard E, Hanaire H, et al. Incremental value of continuous glucose monitoring when starting pump therapy in patients with poorly controlled type-1 diabetes. The Real Trend Study. Diabetes Care 2009;32:2245-50. 